\title{
Commentary
}

\section{Human Histological Research: Is It Necessary? Humane? Ethical?}

\author{
Alden M. Leib* and Charles J. Kowalski ${ }^{\dagger}$
}

A review of the dental literature in the United States over the past 60 years is replete with studies utilizing human histological evidence for research. The first reference found for the use of human tissue for histological study was published in 1941 in the Journal of Dental Research. ${ }^{1}$ Much of this literature focuses on the use of block sections, in which teeth scheduled for extraction are removed along with portions of the surrounding soft tissue and bone in order to study the effects of various interventions. The tissue removed in no way facilitates the surgical extraction of the tooth. It is removed to establish the type of healing, repair, or regeneration by histological evidence. There is no compensating benefit to the patient who, in fact, is put at risk-the removal of the extra tissue may compromise the fit of a subsequent prosthetic restoration. J Periodontol 2005;76:1207-1210.

\section{KEY WORDS}

Histological research; review literature.

\footnotetext{
* Department of Periodontics, Geriatrics and Prevention, University of Michigan, School of Dentistry, Ann Arbor, MI.

$\dagger$ Health Science Institutional Review Board, University of Michigan, School of Dentistry.
}

Tn 1960, Kohler and Ramfjord ${ }^{2}$ published photographs of a maxillary ridge that had one canine removed in block section and claimed that the healing ridge showed "no residual defect." A few years later, concerned about patient disfigurement, Ramfjord and Costich $^{3}$ presented diagrams for the minimally destructive removal of single teeth in block section for histological examination. These studies were done to show healing after gingivectomy and after mucoperiosteal flap procedures. No follow-up study was done to monitor the longer-term effects of the removal of tissue.

In a 1973 study by Dragoo and Sullivan, ${ }^{4}$ block section extractions were performed and they included photographs of the donor sites 5 months post-surgically. The one case they presented had the two maxillary canines removed in block section and the authors stated that there was not extensive loss of ridge height and that an appropriate restoration was constructed. However, there was no follow-up information on the patient's ability to comfortably wear a dental prosthesis.

In 1978 James and McFall ${ }^{5,7}$ published their "method for securing conservative block sections." In their paper, they presented a photograph of a large section taken from the mandibular anterior region. There were no photographs of the donor area after healing and no comments as to whether the surgical extractions compromised the fit of the prosthetic restoration.

Listgarten and Rosenberg, ${ }^{6}$ in 1979 , published histological evidence from human subjects and found that the sites implanted with iliac bone marrow "healed with a true attachment consisting of new bone, new cementum and new periodontal ligament." Six to 12 months post-surgically, suitable restorations were made for these patients to compensate them for their participation. In this study, 25 teeth from 21 patients were obtained, but only 15 blocks from 14 patients could be utilized.

These studies, using block sections from living human beings, were done to verify clinical and radiographic findings and to substantiate research done on animals. Many of these studies did not discuss the patient's healing, disfigurement, or ability to wear dental prostheses. 
It is appropriate to recall the words of Hans Jonas, ${ }^{7}$ a prominent bioethicist, "Let us all remember that a slower progress in the conquest of disease would not threaten society ... but that society would indeed be threatened ... by too ruthless a pursuit of scientific progress (which) would make its most dazzling triumphs not worth having."

The researchers cited here must be questioned for selecting teeth that were untreatable and scheduled for extraction. ${ }^{4,6,8}$ Not only is this a poor excuse, but also a poor choice for experimentation. The teeth utilized were most likely mobile and under traumatic forces. They do not represent suggested or preferred sites for regenerative procedures. Patients who were enlisted for this research may not have been in the best physical condition or may have been heavy smokers. Such compromised patients would never be considered acceptable candidates for most periodontal regenerative procedures.

The NIH has established Regulations and Ethical Guidelines ${ }^{9}$ for research involving human subjects. These well-defined protocols are based on the Nuremberg Code and the Declaration of Helsinki. The Nuremberg Code $^{10}$ on human research, published in 1949, demanded that all human experiments "should be such as to yield fruitful results for the good of society." This code continued, "The experiment should be so conducted as to avoid all unnecessary physical and mental suffering and injury."

The Declaration of Helsinki, first published in 1964 and revised in 1975, 1983, 1989, 1996, and 2000, 16 contains similar guidelines: "Biomedical research involving human subjects must conform to generally accepted scientific principles and should be based on adequately performed laboratory and animal experimentation and on a thorough knowledge of scientific literature...In medical research on human subjects, considerations related to the well-being of the human subject should take precedence over the interests of science and society."

The Belmont Report, ${ }^{12}$ published in 1979, differs from the guidelines mentioned above in that it does not present a list of "dos and don'ts," but rather three principles that govern research with human subjects. These principles are autonomy (respect for persons) beneficence, and justice. According to these principles, subjects should be fully informed about what their participation entails, including risks. They should understand this information and they should be free to participate or not, as they wish.

In the context of research involving block sections, this means that the consent form should clearly state that extra tissue will be extracted for research purposes and that there may be risks in that the fit of prosthetic restorations may be compromised. All other risks associated with the harvesting of extra tissue, over and above the risks associated with extraction per se, must also be delineated. Potential subjects should be able to understand the information imparted to them. It is not enough that the information is in the consent form; investigators have the responsibility to ensure that potential subjects understand this information.

Subjects may also be free to decline participation. This may be problematical if the research is presented as the only avenue available for treatment. If subjects believe that the only way they can be treated is to participate, they may be coerced into participation, and this clearly falls short of the ideal of freedom of choice.

Beneficence goes beyond "do no harm." It urges that we aspire to do good and that the risks associated with the research are justified by the benefits to the participants. Since the removal of extra tissue has no therapeutic motive, this must be justified on the basis of the knowledge to be gained by the experiment. We should be sure that block sections taken in the name of furthering this knowledge could, in fact, provide valid scientific information. The call to minimize risks also requires that we look to other sources of evidence that may be less risky to obtain and less invasive.

Despite these admonitions, there seems to be a sentiment today among many researchers to support the necessity and use of human beings for investigative studies and there has been resurgence in gathering human histological material from block section extractions. The ethical codes and guidelines insist on an investigative panel assessment of human research to determine if experimentation follows ethical guidelines. The Declaration of Helsinki says: "The design and performance of each experimental procedure involving human subjects should be clearly formulated in an experimental protocol. This protocol should be submitted for consideration, guidance, and where appropriate, approval to a specially appointed ethical review committee, which must be independent of the investigator, the sponsor or any other kind of undue influence." 11

However, none of the studies cited above seem to have undergone such evaluation or, if so, this was not indicated in the papers.

In 1989 , Bowers and coworkers ${ }^{13-15}$ published an extensive three-part human histological study evaluating healing in open and closed environments, with and without placement of decalcified freeze-dried bone allografts. Detailed diagrams were presented that displayed the design and dimensions of the block sections taken. Markings, measurements, and histological slides demonstrated and compared the results of all the procedures. Some of the patients in this study had over six block sections taken and after healing, "the patients were referred to the Prosthetic Department for the fabrication of permanent prosthetic appliances." The scientific methods, procedures, and recordings were 
excellent, but, once again, the patient's healing and restorative success was not shown or discussed.

Recently, more advanced regenerative procedures are being utilized. Vincenzi et al. ${ }^{16}$ in 1998, VelasquezPlata et al. ${ }^{17}$ in 2002, and Yukna et al. ${ }^{18}$ in 2002 utilized a refined procedure by filling the defect with regenerative material and covering it with a barrier. After healing, these investigators referred the patients for "prosthetic replacements." No mention of the type of prosthetic appliance was made nor was any followup described. None of these studies showed the donor sites after block sectioning or after healing.

An excellent paper by Lynch ${ }^{19}$ in 1992 reviewed the most well accepted methods for evaluating periodontal wound healing. The advantages and disadvantages were presented for evaluations done by clinical measurements of soft tissue, clinical measurements of hard tissue, radiographic assessment of hard tissue, and histological evidence. It was emphasized that radiography provided the only non-invasive method for evaluating changes in hard tissue.

Lynch, in summary, acknowledged that limited histological evaluation of human tissue "may be justified to demonstrate regeneration of the complete attachment apparatus." This paper also urged the establishment of guidelines by the "investigator and Institutional Review Board for Human Studies which accommodate the needs and rights of the patient."

Nevins et al. ${ }^{20}$ recently published the most detailed study utilizing human block sections. None of the patients were smokers and all were in "good health." Each surgical area was filled with regenerative material, covered by a barrier, and implants were later placed. Although the restorative procedures were "state of the art," there were no photographs of the donor areas before or after implant placement and no longterm follow-up on these patients. This paper set the standard for repair of the donor sites in such procedures and all future investigators should follow this protocol if human studies are deemed necessary.

It is the obligation of dental researchers to determine if block section extractions, even if properly done, restored, and followed up, are of any particular advantage or necessity in determining the value of a procedure or material. Our exuberant quest for scientific knowledge must be tempered by prudence.

Lynch's ${ }^{19}$ sage analysis of scientific proofs has been either forgotten or ignored. He rightly states that human histology is the truest verification of regeneration. However, he also acknowledges that histological procedures are limited, invasive, and must follow ethical guidelines. He and others ${ }^{21-23}$ note that today's sophisticated digital subtraction radiography can detect and quantify periodontal bone healing. Lynch ${ }^{19}$ proposed that proper preclinical animal studies should provide substantial histological data and this, plus clinical and digital radiographic evaluation from human studies, should minimize the need for human histology.

The proof of clinical success in a regenerative procedure is the long-term retention of the tooth with normal function and patient comfort. If a controlled study on a diverse population has retained a statistically significant number of teeth, perhaps we should be able to accept imaging and clinical evaluation as determination of probable success. Can we not draw an analogy with medical research, where it is not necessary to remove an artificial joint to establish histological evidence of success? Here, too, patient comfort and function are the clinical determinants of an acceptable procedure.

For the clinician and the patient, a healthy retained tooth is always considered a favorable outcome whether this is due to true regeneration, connective tissue, or a long junctional epithelium. ${ }^{24}$ Without question, the ultimate scientific proof of regeneration can still only be determined histologically. ${ }^{25}$ However, this information should be obtained from carefully selected and informed human donors whose teeth are properly restored or from post-mortem sections.

It would be hoped that a well-designed study utilizing digital imaging and clinical findings over a suitable length of time would be able to assess the success of a regenerative product. The true efficacy and scientific proof of reattachment in humans could be determined by post-mortem histology. Such a study would require a great amount of time, and time is a rare commodity to the researcher who needs to publish or to the manufacturer who must bring his product to market.

Offering these patients money towards restorative work or providing free restorative care is an enticement to them, but neglects to consider the possible deformation of the ridges that may compromise future denture fit. It is essential that all data collected from such experiments are evaluated and analyzed to determine if the information gained was necessary, of specific value, or unique. It would be beneficial if, as a part of each study, the patients were followed to assess healing, comfort, and long-term success of the prosthetic dentistry that was done.

Ethics aside, block section histological studies should be evaluated on their research merit alone, and we find they fall far short of the "gold standard" for evidencebased research. A recent publication of the evidencebased approach in periodontal research ${ }^{26}$ evaluates all research and determines its hierarchical value. Case series done on limited numbers of non-diverse patients, on hopeless teeth, by various researchers, and without similar protocols may not satisfy statistical demands and may not meet scientific principles.

Once the scientific and legal questions have been posed and answered, we must subject this research to more profound ethical scrutiny. If we accept the use of 
such human experimentation on "condemned" teeth, do we stop here, or perhaps we perform other experiments on the terminally ill, who are "condemned" patients?

\section{REFERENCES}

1. Mann JB, Kaplan H. Histologic studies of block sections of teeth and investing structures removed at intervals following surgical operation. J Dent Res 1941:20: 281(Abstr.).

2. Kohler CA, Ramfjord SP. Healing of gingival mucoperiosteal flaps. J Oral Surg 1960;13:89-103.

3. Ramfjord SP, Costich ER. Healing after simple gingivectomy. J Periodontol 1963;34:401-415.

4. Dragoo MR, Sullivan HC. A clinical and histological evaluation of autogenous iliac bone grafts in humans. $J$ Periodontol 1973;44:599-613.

5. James WC, McFall WT Jr. A method for securing conservative block section in the mandibular anterior region. J Periodontol 1978;49:425-427.

6. Listgarten MA, Rosenberg MM. Histolocal study of repair following new attachment procedures in human periodontal lesions. J Periodontol 1979;50:333-344.

7. Freund PA. Experimentation with Human Subjects. New York: George Braziller; 1970.

8. Common J, McFall WT Jr. The effects of citric acid on attachment on laterally positioned flaps. J Periodontol 1983;54:9-18.

9. National Institutes of Health. Regulations and Ethical Guidelines. Available at http://www.nihtraining.com/ohsrite/ guidelines/helsinki.html. Accessed July 23, 2004.

10. Directives for Human Experimentation. Nuremberg Code, Trials of War Criminals before the Nuremberg Military Tribunals under Control Council Law No. 10. U.S. Government Printing Office. 1949;1:181-182.

11. World Medical Association. Declaration of Helsinki, 6th ed. Edinburgh: World Medical Association 2000. Available at http://www.wma.net/e/approvedhelsinki.html. Accessed July 23, 2004.

12. The Belmont Report. Ethical Principles and Guidelines for the Protection of Human Subjects of Research. The National Commission for the Protection of Human Subjects of Biomedical and Behavioral Research. OPRR Reports April 18, 1979;4-8.

13. Bowers GM, Chadroff B, Carneval R, et al. Histologic evaluation of new attachment apparatus formation in humans, Part I. J Periodontol 1989;60:664-674.

14. Bowers GM, Chadroff B, Carneval R, et al. Histological evaluation of new attachment apparatus formation in humans, Part II. J Periodontol 1989;60:675-682.

15. Bowers GM, Chadroff B, Carneval R, et al. Histological evaluation of new attachment apparatus formation in human, Part III. J Periodontol 1989;60:683-693.

16. Vincenzi G, De Chiesa A, Trisi P. Guided tissue regeneration using a resorbable membrane in gingival recession type defects: A histologic case report in humans. Int J Periodontics Restorative Dent 1998;18:24-33.
17. Velasquez-Plata D, Scheyer ET, Mellonig JT. Clinical comparison of an enamel matrix derivative used alone or in combination with bovine-derived xenograft for the treatment of periodontal osseous defects in humans. J Periodontol 2002;73:433-440.

18. Yukna R, Salinas TJ, Carr RF. Periodontal regeneration following use of ABM/P-15: A case report. Int $J$ Periodontics Restorative Dent 2002;22:146-155.

19. Lynch SE. Methods for evaluation of regenerative procedures. J Periodontol 1992;63(Suppl.):1085-1092.

20. Nevins M, Camelo M, Nevins ML, Schenk RK, Lynch SE. Periodontal regeneration in humans using recombinant human platelet-derived growth factor-BB (rhPDGF-BB) and allogenic bone. J Periodontal 2003;74:1282-1292.

21. White SC, Pharoah MJ. Oral Radiology, Principles and Interpretation, 5th ed. St. Louis: Mosby; 2004.

22. Cope JB, Samchukov ML. Digital subtraction radiography in detection of pericrestal bone-gain. J Periodontal Res 2002;37:147-153.

23. Machtei EE. Outcome variables for the study of periodontal regeneration. Ann Periodontol. 1997;2:229-239.

24. Caton J, Nyman S, Zander H. Histometric evaluation of periodontal surgery II. Connective tissue attachment levels after four regenerative procedures. J Clin Periodontol 1980;7:224-231.

25. ADA Acceptance Program Guidelines for Products Designed to Regenerate Periodontal Tissues. Available at http:www.ada.org/prof/resources/position/standards/ guide_regenerateperio.pdf. Accessed July 23, 2004.

26. Newman MG, Caton JG, Gunsolley JC. The use of the evidence-based approach in a periodontal therapy contemporary science workshop. Ann Periodontol 2003;8:1-11.

Correspondence: Dr. Alden M. Leib, University of Michigan, School of Dentistry, 1011 N. University Ave., Ann Arbor, MI 48109-1078.

Accepted for publication November 24, 2004. 